\title{
O papel da avaliação CAPES no processo de internacionalização da Pós-Graduação em Educação no Brasil (2010-2016)
}

\author{
The role of CAPES evaluation in the internationalization process \\ of Postgraduate Education in Brazil (2010-2016)
}

\author{
Flavia Melville Paiva ${ }^{1}$ \\ ${ }^{1}$ Universidade Federal de Mato Grosso do Sul | Faculdade de Educação | Programa de Pós- \\ Graduação em Educação \\ Campo Grande | MS | Brasil. Contato: flavia.paiva@ufms.br \\ http://orcid.org/0000-0002-3517-5025 \\ Silvia Helena Andrade de Brito ${ }^{2}$ \\ ${ }^{2}$ Universidade Federal de Mato Grosso do Sul | Faculdade de Ciências Humanas | Programa de Pós- \\ Graduação em Educação \\ Campo Grande | MS | Brasil. Contato: silvia.brito@ufms.br \\ http://orcid.org/0000-0002-6186-3980
}

\begin{abstract}
Resumo: Entre as diretrizes que se tornaram importantes para a pós-graduação nos anos 2000, inclusive aquela voltada para a área da Educação, está a internacionalização. Nesse sentido, a internacionalização passou a figurar com um dos elementos valorizados pelas políticas educacionais para a pós-graduação no Brasil. $\mathrm{O}$ objeto deste artigo se volta exatamente para o papel desempenhado pela CAPES, por meio do processo avaliativo que dirige, como indutora do processo de internacionalização da pós-graduação brasileira. O objetivo geral do trabalho é analisar que internacionalização vem sendo valorizada pelas políticas públicas, e seus desdobramentos para a área da Educação. Para tanto, são considerados os documentos que expressam tais políticas, e seus impactos para a pós-graduação em Educação, considerando principalmente a mobilidade docente e discente. Nessa direção, atestam-se as dificuldades decorrentes do fato de que a área Educação não é considerada prioritária no processo de internacionalização em curso, o que se expressa no pouco acesso a recursos para tal, ou a desvalorização da internacionalização Sul-Sul, aquela na qual a área é mais expressiva.
\end{abstract}

Palavras-chave: Internacionalização da pós-graduação. Pós-Graduação em Educação. Avaliação CAPES.

Abstract: Internationalization figures among the guidelines that are important for graduation programs in the 2000s, including the one directed to the area of Education. In this sense, internationalization started to be one of the valued elements in educational policies for graduation in Brazil. This paper deals exactly to the role that CAPES plays, through its evaluation process, as inductor of the process of internationalization of the Brazilian graduation. The aim is to analyze what kind of internationalization has been valued through the public policies, and its deployment to the area of Education. Documents that express such policies are analyzed, and its impacts for the graduation in Education, mainly considering teaching and student mobility. In this perspective, the difficulties observed are mainly due to the fact that the area of Education is not a priority to the current internationalization process, and can be seen by the little possibilities of foment, or the devaluation of the South-South internationalization, the kind of internationalization which is more expressive to the area.

Key words: Internationalization of graduation. Graduation in education. CAPES evaluation.

DOI: http://dx.doi.org/10.1590/S1414-40772019000200009

Este é um artigo publicado em acesso aberto (Open Access) sob a licença Creative Commons Attribution Non-Commercial, que permite uso, distribuição e reprodução em qualquer meio, sem restrições desde que sem fins comerciais e que o trabalho original seja corretamente citado. https://creativecommons.org/licenses/by-nc/4.0/ 


\section{Introdução}

Sobretudo a partir dos anos 2000, vem crescendo a demanda por internacionalização na pós-graduação no Brasil, sendo que no último quadriênio avaliativo - 2013 a 2016 - firmou-se a perspectiva de que o grau de internacionalização de um programa de pós-graduação (PPG) seria requisito sine qua non para a inserção do mesmo no rol de programas considerados de excelência - aqueles que, na avaliação CAPES, lideram o ranqueamento, com notas 6 e 7. Nesse sentido, o documento que norteou a avaliação 2013-2016, publicado em dezembro de 2016, declarava que "Os programas elegíveis [como de excelência] devem demonstrar elevado grau de internacionalização, liderança, nucleação e solidariedade[...]" (CAPES, 2016, p. 21).

Ora, o objetivo central desse artigo, tendo em vista essa diretriz, é indicar em que termos ocorreu a internacionalização da pós-graduação no Brasil, entre os anos de 2010 e 2016, enfocando principalmente a avaliação CAPES como uma política de indução no sentido da internacionalização da pós-graduação em educação no Brasil. A questão central, portanto, é analisar-se que modalidades de internacionalização tais políticas induzem, quando a área do conhecimento em pauta é a educação. Para tal, foram considerados o Plano Nacional de PósGraduação 2011-2020 (PNPG), produzido pelo Ministério de Educação (BRASIL, 2011); a Estratégia Nacional de Ciência, Tecnologia e Inovação 2012-2015 e 2016-2019 (ENCTI), do Ministério de Ciência, Tecnologia, Inovações e Comunicações (MCTIC, 2012; 2016), para o estudo de qual tem sido o entendimento do Estado sobre a internacionalização, ao longo dos seis anos propostos para estudo; as Fichas de Avaliação dos programas de excelência da área Educação (triênios 2007-2009 e 2010-2012) e os Documentos de Área do Sistema Nacional de Pós- Graduação da Capes para a área Educação (SNPG) (2013; 2016). Como referências teóricas utilizadas para a análise foram mobilizados os trabalhos de Azevedo e Catani (2015), Dourado, Oliveira e Catani (2003), França, (2014), Morosini (2006), Paiva (2017), Peixoto (2010), Silva Junior e Kato (2012) e Visentini (2013).

A partir destes elementos, o artigo divide-se em três partes. Na primeira, são apresentados os parâmetros que, a partir dos textos institucionais, vêm norteando as políticas de internacionalização da pós-graduação, inclusive a avaliação desse processo; um segundo momento, no qual se discute o que os Programas de Pós-Graduação em Educação realizaram, em termos de internacionalização, visando atender, as diretrizes da avaliação CAPES, considerando-se as especificidades da área, no rol do campo científico no Brasil. Por fim, este trabalho é concluído com algumas observações sobre desafios que se colocam no contexto da pós-graduação em educação no Brasil, sobretudo para o quadriênio iniciado em 2017. 


\section{As políticas de internacionalização da pós-graduação no Brasil: marcos institucionais}

Considerando o momento histórico pelo qual passa a sociedade capitalista, a internacionalização da educação superior tornou-se cada vez mais presente enquanto diretriz das políticas públicas voltadas para essa etapa da escolarização, em todo o mundo, sobretudo a partir da década de 1990. Ora, nesse novo marco do processo de globalização do capitalismo, decorrente do caráter contraditório da própria sociedade no qual estão imersas, pelo menos dois entendimentos distintos do que seja a internacionalização da pós-graduação se fazem presentes, sugerindo o questionamento se a educação é serviço ou bem público. Por um lado, citamos Peixoto $(2010$, p. 32), que defende a necessidade de se diferenciar internacionalização de transnacionalização ou liberação da educação superior, conceituando internacionalização da educação superior como sendo o

[...] processo de integrar a dimensão internacional às funções de docência, pesquisa e serviços que as instituições de educação superior desempenham e seu uso está mais estritamente relacionado com o valor acadêmico das atividades internacionais do que com uma motivação econômica. (PEIXOTO, 2010, p. 33).

Segundo o mesmo autor, ao se aproximar da categorização de educação como bem público, a internacionalização decorreria da própria missão da universidade, sendo entendida como cooperação internacional horizontal, visando a produção conjunta de conhecimento.

Ora, tal ênfase se contraporia, ao entendimento da educação como serviço ou mercadoria global, proposta perpetuada pela perspectiva neoliberal de mundialização, na qual ciência e tecnologia se tornaram insumos produtivos que garantem a empresas de países mais desenvolvidos assumirem o controle do mercado. Para tal, é importante propor formas de gerar “eliminação de barreiras para incrementar o movimento dos serviços educativos, facilitar o estabelecimento de filiais de universidades estrangeiras, executar a cooperação dominada por critérios assistenciais, vender franquias acadêmicas, criar universidades corporativas, programas multimeios e universidades virtuais" (PEIXOTO, 2010, p. 33).

Nesse contexto, percebemos que a motivação à internacionalização da educação superior, enquanto fenômeno educacional, chegou às instituições de educação superior de formas distintas, embora voltada para a mesma exigência de produção, geração de conhecimento, publicações em parceria, organização de eventos, e a consequente avaliação das instituições quanto à internacionalização do saber e inserção internacional. É o que Dourado, Oliveira e Catani (2003, p. 19-20) resumem ao afirmar que em nosso momento de reestruturação capitalista, "compete à universidade contribuir significativamente com a produção de mais-valia relativa, ou seja, ela deve formar profissionais e gerar tecnologias e 
inovações que sejam colocadas a serviço do capital produtivo”. O problema desta priorização, quando a ênfase passa a ser produzir conhecimento como insumo produtivo, é que a universidade passa a ser avaliada como produtiva ao vincular "sua produção às necessidades do mercado, das empresas e do mundo do trabalho em mutação", o que tem como implicação "minar as bases da universidade como espaço privilegiado de produção de conhecimento".

Assim, é fato que tanto o Ministério da Educação (MEC), quanto o Ministério da Ciência, Tecnologia, Inovações e Comunicações (MCTIC) tem incentivado a internacionalização da pós-graduação, utilizando para tal vários mecanismos, como o Programa de Estudantes-Convênio de Pós-graduação (PEC-PG), Programa de Doutorado Sanduíche no Exterior (PDSE), e Programa Ciência sem Fronteiras (CsF). Ainda mais efetivamente, na medida em que a internacionalização, a partir dos eixos anteriormente descritos, coloca-se explicitamente como critério de avaliação para os programas de excelência (CAPES, 2016), essa perspectiva foi ainda mais reforçada.

Visando mostrar essas diretrizes, propõe-se neste artigo a análise sucinta de dois documentos, em ordem cronológica, para entendermos como a internacionalização da pósgraduação veio sendo construída no período de 2010 a 2016: o VI Plano Nacional de PósGraduação, de 2011; e a atual Estratégia Nacional de Ciência e Tecnologia 2016-2009 (BRASIL, 2016).

O VI Plano Nacional de Pós-Graduação (PNPG 2011-2020) tem como objetivo a busca mais explícita do crescimento equânime do sistema nacional de pós-graduação, ou seja, a diminuição das diferenças regionais, procurando "atender com qualidade as diversas demandas da sociedade, visando ao desenvolvimento científico, tecnológico, econômico e social do país", subsidiando "a formulação e a implementação de políticas públicas voltadas para as áreas de Educação, ciência e tecnologia (BRASIL, 2010a, p. 27-29). Da mesma forma, sobressai, neste último PNPG, a preocupação com a internacionalização.

Aliás, frise-se que o VI PNPG foi o primeiro destes documentos a dedicar um capítulo exclusivamente à internacionalização, declarando ser este o desafio maior do Brasil no século XXI. Nesta direção, foram sugeridas algumas ações que colocariam o Brasil em evidência no cenário internacional: ser o celeiro agrícola mundial, buscar padrões demográficos como os europeus e norte-americanos, e aceitar o desafio de construir a sociedade de bem-estar. Com referência especificamente à pós-graduação, salientava-se que seu núcleo seria a pesquisa e que se considera que o Brasil já possuía condições para criar a sociedade do bem-estar.

Para que a internacionalização da pesquisa se efetive, recomenda que sejam implementadas parcerias entre universidade, Estado e empresas, um modelo denominado pelo 
VI PNPG de "tríplice hélice", baseado na Agenda Nacional de Pesquisa e na participação de todas as agências federais e estaduais de fomento (BRASIL, 2011) ${ }^{1}$. Nesse delinear de objetivos e desafios para o Brasil no período de 2011 a 2020, Andrade (2012) identifica como papel do Estado, no âmbito da política internacional: assumir, perante as empresas econômicas mais relevantes no processo de expansão e acumulação do capital, o papel de facilitar a expansão mais monopolista possível do capital no exterior. E que as formas e recursos que o Estado vem utilizando para esse feito têm sido decorrentes de sua realidade histórica, mas que levam o Estado a afirmar, com todos os recursos à sua disposição, os interesses monopolistas do capital.

Assim, o VI PNPG não foge das propostas relacionadas à internacionalização da educação quando assume o interesse neoliberal de inclusão do Brasil no capitalismo transnacional, globalizado. Seu foco inicial foi concentrar-se no "exame da produção científica, enquanto medida da presença internacional da ciência brasileira, para posteriormente abordar as ações e mecanismos de cooperação internacional e suas sinergias com as atividades de publicação" (BRASIL, 2010a, p. 223), numa proposta clara de busca de participação nos grandes blocos capitalistas, e não de apoio ao desenvolvimento mundial inclusivo.

Nessa direção, o capítulo 11 do VI PNPG, denominado "Internacionalização da Pósgraduação e a cooperação internacional (presença internacional da ciência e da tecnologia brasileiras)", mostra dados da evolução da ciência brasileira em termos qualitativos e quantitativos nas últimas décadas, ou seja, como o país tem se comportado quanto aos impactos relativos às 23 áreas de conhecimento consideradas de grande importância para o setor produtivo: Biologia e Bioquímica; Biologia Molecular; Biologia Molecular e Genética; Ciência da Computação; Ciência dos Materiais; Ciências Agrícolas; Ciências da Flora e da Fauna; Ciências Ecológicas e do Ambiente; Ciências Espaciais; Ciências Sociais; Economia e Administração; Engenharias; Farmacologia; Física; Geociências; Imunologia; Matemática; Medicina Clínica; Microbiologia; Neurociências; Neurociências e Comportamento; Psicologia/Psiquiatria; Química, classificadas pelo Institute for Scientific Information - ISI. Ressalta-se principalmente o impacto relativo às publicações brasileiras que, conforme o Plano,

\footnotetext{
${ }^{1}$ Tal estratégia, levada à frente pelo Programa Ciência sem Fronteiras, permitiu a condução de ações induzidas e parcerias entre as universidades e os setores público e privado, tendo o apoio do MEC e do MCTIC. As parcerias com o setor privado ocorreram sob a forma de empresas financiadoras e empresas parceiras. As financiadoras: BG Group, Boeing, Eletrobrás, Funttel, Hyundai, Natura, Petrobrás, Posco, Vale, Andima, BM\&FBOVESPA, Cetip, CIP, Federação Brasileira de Bancos (Febraban), Rede e Statoil Brasil. As parceiras eram a Associação Brasileira da Infraestrutura e Indústrias de Base (Abdib), Amcham Brasil, Agência Nacional de Petróleo, Gás Natural e Biocombustíveis, Confederação Nacional da Indústria (CNI/ Senai), Confederação Nacional do Transporte, Herbalife e Telecom Italia Mobile (TIM).
} 
em áreas como Física, Matemática, Ecologia e Geociências, têm se situado próximas das médias mundiais. Um exemplo é que, em termos quantitativos, o Brasil ocupava a $13^{a}$ posição no ranking de países em números de artigos publicados, (BRASIL, 2010a, p. 229), considerando os países que compõem o G8+5 $5^{2}$ Vale aqui ressaltar que o VI PNPG, apesar de ser documento político produzido pelo MEC, não inclui a Educação entre as 23 áreas de conhecimento apontadas para a análise da internacionalização realizada.

Concluindo, o Plano Nacional de Pós-Graduação 2011-2020 conceitua o termo internacionalização da pós-graduação, em vias gerais, como ferramenta para que o país se coloque em posição de destaque no mercado econômico mundial, produzindo tecnologia. Em se tratando da questão do mercado, como indicadores de internacionalização, valoriza a produção científica internacionalizada e a participação em academias de ciência. Sugere linhas de ação bem direcionadas à participação em grupos de pesquisa internacionais e à divulgação científica das pesquisas, mas salientando priorizar certas áreas de conhecimento, como afirmado anteriormente. Também com a perspectiva de incentivar a participação em grupos de pesquisa internacionais, o VI PNPG fomenta a mobilidade internacional de pesquisadores, mas não especificamente apenas de docentes das instituições de ensino superior. Sugere várias possibilidades de pesquisa em território brasileiro, sendo a pós-graduação mais um desses lócus de produção de conhecimento, principalmente daquele relacionado à produção de patentes.

Assim, Silva Junior e Kato (2012) têm razão ao constatar que a internacionalização e mercantilização do conhecimento, assim como a certificação em massa, estão evidentes no PNPG. Os autores asseveram que, com o PNPG, "a universidade tornou-se linha de continuidade do Estado, um instrumento de produção direcionado para o capital financeiro mundializado" (SILVA JUNIOR; KATO, 2012, p. 12). Segundo eles, temos no VI PNPG um documento que sugere, por um lado, o fortalecimento da relação entre universidade e sociedade, com vistas a dinamizar o Sistema Nacional de Pós-Graduação, buscando o aumento da produção e de sua apropriação pública, fazendo com que as instituições universitárias participem na formulação e implementação de metas nacionais de desenvolvimento. Tal intento, por outro lado, não se coloca a serviço da cidadania, mas do desenvolvimento e crescimento do capital, amparado pela internacionalização, sobretudo do capital internacional.

\footnotetext{
${ }^{2}$ O G8+5 é constituído por presidentes e outros cientistas das Academias de Ciências dos oito países capitalistas mais desenvolvidos e cinco economias emergentes: África do Sul, Alemanha, Brasil, Canadá, China, Estados Unidos, França, Índia, Itália, Japão, México, Reino Unido e Rússia.
} 
Sinalizam, dessa forma, que as áreas de conhecimento com pesquisa em pós-graduação devem priorizar o atendimento às empresas públicas e privadas, ou seja, o mercado profissional. A internacionalização entra como ação necessária para integrar instituições brasileiras e internacionais, para fomentar a circulação e a ampliação do conhecimento científico, principalmente nas áreas menos desenvolvidas em termos de tecnologia e inovação. Tal discurso novamente autoriza os órgãos de fomento a priorizarem o financiamento para áreas de conhecimento específicas, como tem sido feito historicamente no Brasil e, mais densamente, pelos programas de incentivo à internacionalização atualmente em vigor. Tais afirmações fortalecem o questionamento inicial desta pesquisa, de ver como áreas de conhecimento são induzidas à internacionalização e têm internacionalizado seu saber científico, sem ser prioridade 1 na Capes e no CNPq, como é o caso da educação.

Já o documento intitulado Estratégia Nacional de Ciência, Tecnologia e Inovação (ENCTI), que lista as áreas prioritárias do governo brasileiro para investimento em Ciência, Tecnologia e Inovação (CT\&I) para o período 2016-2019 (BRASIL, 2016), serve de base para detectar as diretrizes do MCTIC para o desenvolvimento da ciência e tecnologia e como ele trata a internacionalização da pós-graduação nesta política.

A ENCTI 2016-2019 (BRASIL, 2016) foi aprovada em março de 2016, durante a crise política em curso no Brasil, que culminou com a destituição da presidente do país. O texto da ENCTI 2016-2019, dando continuidade às questões tratadas pelo documento que lhe antecedeu, cita o Brasil como já sendo participante do grupo de países em constante investimento em CT\&I e que tem, desde os anos 2000, vivenciado o crescimento das universidades, a modernização dos laboratórios, a contratação de pesquisadores e o surgimento de novos instrumentos de financiamento, bem como a maior projeção internacional das pesquisas brasileiras, pela sua publicação (BRASIL, 2016). No entanto, como o investimento teria sido menor na primeira década do século XXI, conclama por maior atenção à expansão das ações para fomento à CT\&I.

Com o objetivo de avaliar como a ENCTI 2016-2019 tratou a internacionalização, destaca-se três eixos trabalhados por ela: A. Competitividade ou cooperação; B. Educação, pesquisa e pós-graduação e C. Mercado internacional:

A) Competitividade ou cooperação: A ENCTI 2016-2019 sugere uma internacionalização com base na busca pela participação em um mundo globalizado e pelo reconhecimento da competitividade internacional, simultaneamente à cooperação internacional (BRASIL, 2016).

Conforme mostrado anteriormente, o desenvolvimento capitalista mostrou como é impossível buscar atingir estes dois objetivos tão contraditórios, que se expressariam pela 
excelência na concorrência no mercado de CT\&I, sendo ao mesmo tempo solidário com países mais pobres ou menos desenvolvidos. Tal contradição tem sido resolvida tão somente pela valorização de uma busca por apoio de países desenvolvidos; ou, no máximo, com o apoio a países menos desenvolvidos em determinadas áreas, mas nas quais se atua com objetivos imperialistas, conforme tratado por Harvey (2004).

Ora, Azevedo e Catani (2015) haviam analisado a ENCTI anterior (2012-2015), em que ocorria a mesma contradição entre incentivo para competitividade e cooperação, levando a projetos excludentes, ao se pretender associar solidariedade internacional e concorrência, em um mercado global de educação e conhecimento. Essa contradição, como frisado, reaparece na ENCTI 2016-2019, justificada pela tentativa retórica de propor uma internacionalização via cooperação internacional, para se adentrar no mercado global em iguais condições de concorrência. A cooperação é justificada ao assumir que o Brasil já detém tecnologia passível de ser compartilhada com outros países, tanto para apoio ao desenvolvimento de países menos estruturados, como em pesquisas com pares desenvolvidos. O exemplo são as atividades brasileiras no Atlântico Sul (BRASIL, 2016), que já possibilitaram a assinatura de dois instrumentos de cooperação internacional em 2015: uma declaração com a África do Sul, iniciando uma aliança inicialmente com Argentina, Angola e Namíbia; e uma declaração de intenções entre o MCTIC e a União Europeia, para o desenvolvimento de expertise conjunta e conhecimento científico sobre o Oceano Atlântico. Outros exemplos citados estão nas áreas de agropecuária (liderança científica e domínio tecnológico), de saúde (tratamento de doenças tropicais e negligenciadas) e nos setores aeronáutico, nuclear, e de petróleo e gás (BRASIL, 2016). Estes e outros exemplos, como o relacionado à política energética, com o apoio ao desenvolvimento de fontes renováveis de energia eólica, corroboram para que o investimento sugerido seja priorizado para certas áreas de conhecimento: agrárias, tecnológicas e saúde, principalmente. Sempre se salienta que o interesse é reunir esforços para fomentar um desenvolvimento tecnológico atrelado à inovação, encaminhando as iniciativas para a realização de seminários temáticos e setoriais, incentivo a publicações e feiras tecnológicas, acesso a parcerias com outros países, em cooperação internacional. Com isso, pretende-se reduzir assimetrias regionais na produção e no acesso a CT\&I, principalmente com a inserção brasileira nas "cadeias globais de valor e para o avanço da fronteira do conhecimento científico e tecnológico" (BRASIL, 2016, p. 67).

Um dos principais objetivos seria a "cooperação internacional com países e instituições líderes nas áreas estratégicas". Além disso, a competitividade é justificada como necessária para o avanço da inovação, principalmente em áreas em que o nosso país tem importância além de 
suas fronteiras nacionais, como o mercado brasileiro do petróleo e gás, salientando que o incentivo precisa atender ao desenvolvimento da cadeia nacional de fornecedores, para consequente atendimento das demandas internacionais. Além das áreas já elencadas, também são citadas a bioeconomia, a tecnologia de informação e comunicação, e a questão energética (LIMA, 2008; GOUVEIA, 2010) ${ }^{3}$, e para fomentar o desenvolvimento das cadeias produtivas, pretende-se investir para a "redução da dependência externa e a solução de desafios tecnológicos para os problemas estruturais do tecido industrial e produtivo brasileiro" (BRASIL, 2016, p. 109), sempre com vistas a posicionar o país entre os mais desenvolvidos em CT\&I. Ou seja, a proposição é conduzir o país ao rol das nações mais desenvolvidas, por meio do "fortalecimento dos think tanks ${ }^{4}$ (LEIS, 2017) nacionais que, produzindo e difundindo conhecimentos sobre assuntos estratégicos, possam identificar tendências e propor ferramentas que contribuam para a tomada de decisão sobre os investimentos internos e os rumos da cooperação internacional. Dentre estas mentoras das think tanks, teríamos as universidades como produtoras de conhecimento, e nesse ponto a ENCTI 2016-2019 faz menção à importância da educação, pesquisa e pós-graduação para a cooperação.

B) Educação, pesquisa e pós-graduação: Em relação ao tema educação, a ENCTI 20162019 reconhece que o desenvolvimento social incluiria, além do quesito renda, dois outros pilares: 1. Os serviços básicos e 2. As condições de sustentabilidade e prática de novos métodos e técnicas que atendam às "demandas sociais, especialmente nas áreas de Educação, saúde, habitação, segurança, mobilidade urbana e energia" (BRASIL, 2016, p. 68). Confirma, assim, a importância de desenvolver e disseminar novas tecnologias como estratégia para a redução da exclusão social e das desigualdades de oportunidade e de exclusão ocupacional. Para tanto, considera que a "elevação da qualidade da Educação passa pela valorização da cultura científica

\footnotetext{
${ }^{3}$ Ao tratar da temática energética, é quase impossível deixar de citar o caso da exploração do pré-sal. Segundo

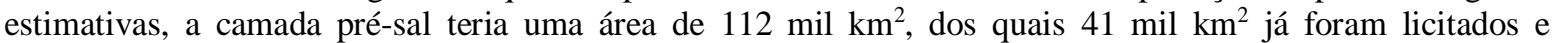
concedidos. A Agência Nacional do Petróleo, Gás Natural e Biocombustíveis (ANP) e a Petrobras foram as responsáveis pelo mapeamento, bem como pelo desenvolvimento de tecnologia para a exploração dos blocos em que a Petrobras era a operadora principal, considerando-se que a Petrobras era, até 2018, a empresa operadora da maioria dos blocos já concedidos na área do pré-sal. Conforme dados da própria Petrobras, entre 2006 e 2009 , a empresa investiu cerca de $\mathrm{R} \$ 1,8$ bilhão em universidades e institutos de pesquisa brasileiros, que operaram em parceria, visando criar tecnologia para prospecção de petróleo em águas profundas. A mudança nos marcos regulatórios a partir de 2018, compatível com a proposta da ENCTI 2016-2019, desobriga a Petrobras de participar de todas as concessões, aumentando ainda mais a presença do capital privado, o que também deve levar ao menor investimento do país em CT\&I nesse setor.

${ }^{4}$ Think tank pode ser definido como uma instituição que se dedica a produzir e difundir conhecimentos e estratégias inovadoras, sobre assuntos políticos, econômicos ou científicos, sobre os quais outras instâncias de elaboração (estados, associações de classe, empresas ou universidades), ainda não se pronunciaram. Visam, dessa forma, fornecer insumos para se pensar, de forma ágil, sobre questões de interesse da sociedade.
} 
por meio de ações que alcancem todas as camadas sociais, em todo o território nacional", relacionando a priorização à Educação científica como elemento importante para atrair mais jovens para as carreiras de CT\&I, sugerindo o apoio às práticas empreendedoras, mesmo antes de atingir a pós-graduação.

Ao tratar dos exemplos de tais iniciativas, o ENCTI 2016-2019 menciona as várias instituições de ensino superior internacionais que propuseram cooperação financiada pelo governo brasileiro, principalmente por meio do Programa Ciências sem Fronteiras. Em outras palavras, a internacionalização possível para a Educação seria aquela que beneficiaria mais uma vez o capital privado, dessa vez das IES estrangeiras, por meio de financiamento com fundos públicos. E como a questão é a educação tecnológica, visa- se a formação de quadros para as mesmas áreas prioritárias, citadas anteriormente. A busca, neste momento, seria para que o Brasil se firme como nação soberana e capaz de interagir com o cenário internacional contemporâneo (BRASIL, 2016), contradizendo a sua assunção anterior de que já estamos incluídos e soberanos internacionalmente, neste século XXI.

Para concluir, é interessante salientar como incentivam a formação de dois atores na Educação científica para a inclusão de todas as camadas sociais e em todo o Brasil: o divulgador e o professor de ciências, e que "As universidades e instituições de pesquisa precisam ser estimuladas a incorporar a dimensão social nas suas agendas de pesquisa, a promover a formação cidadã; e deve ser buscada uma maior integração das ciências sociais e humanas às políticas de CT\&I" (BRASIL, 2016, p. 94-96). A ENCTI 2016-2019 exprime, assim, duas vertentes distintas para o tratamento da Educação: a Educação científica e a Educação básica. A primeira tem o objetivo de formar os quadros que se desenvolverão, em diferentes níveis, com a ciência e a tecnologia; a segunda é dispensada a todo cidadão. A Educação científica forma para o trabalho complexo e internacionalizado; a básica, para o trabalho simples (a exemplo do professor de ciências), sempre atendendo aos interesses e demandas do capital (NEVES; PRONKO, 2008).

A primeira, voltada para a formação do pesquisador, teria seu locus na pós-graduação. A ENCTI 2016-2019, ciente da tendência de vários governos internacionais de atrair investimentos internacionais em indústrias de alta tecnologia, em áreas específicas como "equipamentos de telecomunicações, farmacêutica, aeroespacial, além de serviços e telecomunicações empresariais" (BRASIL, 2016, p. 53), explica a razão de que investimentos em pesquisa para a colaboração internacional têm sido estabelecidos em cooperações mais flexíveis, capazes de agregar vários parceiros internacionais. Percebe-se, contudo, a manutenção de papéis distintos nessa cooperação, que define de forma hierárquica a posição dos distintos países - aqueles que definem objetos e 
objetivos de pesquisa, de acordo com seus interesses e demandas; e os que se colocam numa posição subordinada, de cooperação.

Nesse cenário de colaboração internacional, para que pesquisadores alcancem resultados não mais apenas por esforços domésticos, mas agregando tecnologias, a ENCTI 2016-2019 referese mais uma vez a pós-graduação, entendida como lócus da maioria da produção científica no país, com destaque à participação dos docentes das instituições públicas de ensino superior. Quanto a investimentos, assume que, desde 2000, o Brasil tem investido na "expansão do sistema universitário e na modernização dos institutos públicos de pesquisa" (BRASIL, 2016, p. 75) e que os dispêndios para investimento em CT\&I do Governo Federal aumentaram de 5,8 bilhões de reais, em 2000, para 32,9 bilhões em 2014, principalmente aportados pelo MEC e MCTIC, o que comprovaria a importância da pós-graduação para o Sistema Nacional de Ciência, Tecnologia e Inovação (SNCTI). Assim, o documento destaca que o investimento via MEC e MCTIC tem tomado forma no apoio a pesquisadores, pela concessão de bolsas de diversas modalidades e finalidades, em que beneficiários são estudantes do nível médio e de graduação, para despertar vocações científicas e incentivar a formação de talentos; e para a pós-graduação, com o intuito de formação de recursos humanos. Em termos internacionais, tais bolsas visam à mobilidade como forma de “internacionalizar o ensino superior e a pesquisa pública, permitindo aos pesquisadores desenvolver novas habilidades e obter novos conhecimentos" (BRASIL, 2016, p. 55).

Sobre a formação de recursos humanos e o papel da pós-graduação, pondera-se que a formação de quadros com titulação tem sido predominante no que chama de unidades de referência do SNCTI, ou seja, IES e institutos de pesquisa. No entanto, dos participantes do grupo Pesquisa, Desenvolvimento e Inovação nas empresas, em 2011, somente 16,4\% eram pós-graduados, sugerindo a necessidade de maior presença de titulados nos ambientes de inovação empresarial, assim como nos setores de administração do SNCTI.

Em relação à formação de recursos humanos com vistas à internacionalização, o Programa Ciência sem Fronteiras foi avaliado como um "avanço na internacionalização da pesquisa brasileira", por ter enviado estudantes brasileiros para outros países, mas sempre nas áreas consideradas prioritárias, excluindo-se basicamente as Ciências Humanas e Sociais ${ }^{5}$. Informa que não somente o governo federal e governos estaduais têm verbas disponibilizadas para a internacionalização, mas existem outras fontes: "Horizon 2020 (Comunidade Europeia), Newton Fund e Prosperity Fund (Reino Unido), Global Environment Facility - GEF

\footnotetext{
${ }^{5}$ Devemos salientar que, para 2016, último ano de existência do programa, o CsF já foi publicamente direcionado para a Pós-graduação, deixando de investir na formação de jovens talentos na graduação.
} 
(Internacional), German Climate and Technology Iniciative - DKTI e Internacional Climate Iniciative - IKI (Alemanha), entre outros" (BRASIL, 2016, p. 25).

Em relação ao mercado internacional, a ENCTI 2016-2019 reafirma sua importância novamente, lembrando que é para o mercado internacional que as novas tecnologias são direcionadas, assim como o conhecimento científico e a priorização de investimentos em determinadas áreas de conhecimento. No documento, fica mais clara a sua centralidade quando se trata de pensar um "sistema montado para fazer o país inovar" (BRASIL, 2016, p. 9-10), citando como exemplo os parques tecnológicos em operação no Brasil, criados como ambientes "cooperativos controlados para empresas de base tecnológica", que colocam o país em posição promissora, incluindo, as mais de 400 empresas incubadoras brasileiras existentes em 2016. Dessa forma, o documento reapresenta o conceito de que a inovação é o caminho para que o país esteja no século XXI, incluído e operante, soberano e em pé de igualdade. Esta era, de fato, a imagem que a ENCTI 2016-2019 tentava registrar: o Brasil seria uma potência emergente, com uma economia em expansão e uma projeção mundial reconhecida pelas potências tradicionais (VISENTINI, 2013), necessitando recursos robustos para o incentivo nacional e consequente apoio internacional. Entre as diversas imagens sugeridas para o Brasil, contraditórias quando se trata de competição e cooperação, percebemos a de estar ciente da necessidade de acesso e adesão ao mercado internacional, atendendo ao desafio imposto pela globalização. Isto, no contexto do capital, estará sempre presente, embora contraditoriamente apresente a imagem do país vitorioso, de um lado (competição); e daquele que ainda precisa conquistar seu espaço entre as nações mais desenvolvidas, por outro (cooperação).

Consideradas essas diretrizes em termos de CT\&I, como está a questão da avaliação CAPES, no cenário de indução, via Estado, no sentido de internacionalização da pós-graduação, em particular para a área da Educação? Esse será o foco da segunda parte deste artigo.

\section{A internacionalização como demanda da avaliação CAPES para a área de Educação}

Partindo da avaliação do último quadriênio, a Pós-graduação stricto sensu em Educação contava, em setembro de 2016, com 246 cursos de Pós-graduação, sendo 128 mestrados acadêmicos, 74 doutorados e 44 mestrados profissionais. Tais cursos estavam organizados em 170 programas de Pós-graduação, sendo 74 com mestrado e doutorado, 54 de somente com mestrado e 44 de mestrado profissional. Comparando esta última informação com os dados publicados na avaliação de 2007, vemos que a área de Educação teve um aumento de 78 programas para 170 em 2016, ou seja, um crescimento de 120,5\% em dez anos. 
O Documento de Área 2016 (CAPES, 2016) explicita como essa expansão ${ }^{6}$ se deu dentro dos períodos avaliativos da Capes, ou seja, a distribuição pelas regiões brasileiras e quanto à dependência administrativa. Em linhas gerais, destaca:

a) Crescimento quantitativo da área: o número de Programas de Pós-graduação aumentou em 121,6\%, da trienal 2007 para 2016, sendo que os de Mestrado Acadêmico tiveram incremento de 64,1\%; e os de Doutorado, de 124,2\%. No caso dos Mestrados Profissionais, na trienal de 2013 eram nove cursos; em setembro de 2016, 44 (388,9\% de aumento $)^{7}$.

b) Dependência administrativa: a expansão ocorreu mais fortemente nas IES públicas (de 72 em 2007 para 163 em 2016, aumento de 126,4\%). Nas privadas, passou-se de 39 Programas em 2008 para 83 em 2016 (113,0\%).

c) Regionalização: expansão dos programas da trienal 2007 para o ano de 2016 atingiu todas as regiões: na Região Norte, foi de $300,0 \%$ (de três para 12); no Nordeste, de $191 \%$ (de 11 programas para 32); no Centro-Oeste, de 128,0\% (de sete para 16 programas em 2016); no Sul, de 121,0\% (de 19 para 42); e na região Sudeste de 84,0\%, passando de 38 para 70 programas.

Os dados de estratificação dos Programas de Pós-graduação em Educação nas Trienais 2007, 2010 e 2013, elemento particularmente importante já que a internacionalização é um quesito, como já comentado, relevante sobretudo para os programas de excelência da área aqueles que receberam notas 6 e 7 no quadriênio 2013-2016, revelam uma pequena modificação em quase todos os estratos: 1 . Aumento da porcentagem nos estratos 3, de 25,6\% para 38,0\% e 7, de $0,0 \%$ para $2,5 \%$; 2. Diminuição dos estratos 4,5 e 6 , sendo mais significativa no 4, com decréscimo de 51,3\% em 2007 para 40,5\%, em 2013. Os estratos relacionados à excelência (6 e 7) sofreram alguma modificação, caminhando para a manutenção da porcentagem de 5,0\% para o estrato 6 e 2,5\% para o 7, conforme demonstrado na tabela 1 .

Assim, em linhas gerais, a quantidade de programas de Pós-graduação em Educação passou de 78 em 2007 para 170 em 2016, mas não trouxe grande diferença na divisão ou na avaliação da qualidade dos programas na estratificação 6 e 7, promovida pelo Sistema Nacional de Pós-Graduação da Capes, que sofreu uma variação pequena neste período (passando de 5

\footnotetext{
${ }^{6}$ A expansão ainda continua. A título de exemplo, a Pós-graduação stricto sensu em Educação contava, em abril de 2017, com 249 cursos, sendo 130 mestrados acadêmicos, 74 doutorados e 45 mestrados profissionais, incluídos em 177 programas de Pós-graduação, sendo 74 com mestrado e doutorado, 56 somente com mestrado e 47 de mestrado profissional. Comparando esta última informação com os dados publicados na avaliação de 2007, temos que a área de Educação saltou de 78 programas para 177 em 2017, ou seja, ampliou 126,9\% em dez anos, com 6,4\% somente entre 2016 e abril de 2017.

${ }^{7}$ Não foi possível estabelecer uma comparação para o período 2007/2016 em relação aos Mestrados Profissionais, pois estes últimos surgiram após a avaliação de 2010 .
} 
programas com nota 6 em 2007, para 7 nota 6 em 2016; e de 0 programas nota 7 em 2007, para 2 nota 7 em 2016).

Tabela 1 - Estratificação dos Programas de Pós-graduação em Educação nas trienais 2007, 2010 e 2013 (\% por estrato)

\begin{tabular}{c|c|c|c|c|c}
\hline \multirow{2}{*}{ Avaliação } & \multicolumn{5}{|c}{ Extratos } \\
\cline { 2 - 6 } & 3 & 4 & 5 & 6 & 7 \\
\hline 2007 & 25,6 & 51,3 & 16,7 & 6,4 & 0,0 \\
\hline 2010 & 31,5 & 45,7 & 14,1 & 5,4 & 3,3 \\
\hline 2013 & 38,0 & 40,5 & 14,0 & 5,0 & 2,5 \\
\hline 2016 & 30 & 44,1 & 20,6 & 4,1 & 1,2 \\
\hline
\end{tabular}

Fonte: CAPES. Documento de área 2017 - Educação. Brasília, 2017. Disponível em:

http://avaliacaoquadrienal.capes.gov.br/. Acesso em: 29 set. 2017. Organização: Paiva (2017).

Em 2016, o documento de Área indicou os seguintes eixos para a internacionalização dos programas de excelência:

A internacionalização, na área de educação, vem sendo desenvolvida em torno dos seguintes eixos:

a) O primeiro diz respeito à internacionalização realizada, principalmente, por meio de publicações em livros e periódicos internacionais. Trata-se de resultados de pesquisas individuais ou de grupos de professores e pesquisadores publicados em periódicos internacionais de qualidade;

b) $\mathrm{O}$ segundo caracteriza a internacionalização como o desenvolvimento de pesquisas e outras atividades em rede que exigem maior envolvimento institucional do Programa e das IES. Dentre os produtos desse eixo estão também livros conjuntos e artigos em periódicos;

c) $\mathrm{O}$ terceiro diz respeito à atuação de pesquisadores e professores brasileiros em programas estrangeiros, na qualidade de professores visitantes, assim como de pesquisadores estrangeiros nos programas no Brasil. Nesta última modalidade, ganham destaque os cursos oferecidos nos programas de pós-graduação; e

d) O quarto eixo vem sendo desenvolvido por meio da cooperação internacional, envolvendo trânsito de alunos. Nessa linha, há cooperações com programas mais consolidados tanto nacionais quanto internacionais e recepção de alunos em programas do tipo sanduíche. Paralelamente, é ainda valorizada a relação com países menos desenvolvidos, na forma de programas de cooperação para formação em atividades desenvolvidas com a África e alguns países da América Latina. (CAPES, 2016, p. 20-21).

Para a mensuração do grau de internacionalização dos Programas, a área utilizou como indicadores, para cada programa: 1. a mensuração de pós-doutoramentos e de participações, como professor visitante, do corpo docente do programa em centros de excelência no exterior; 2. o volume de professores estrangeiros visitantes recebidos; 3. O intercâmbio de alunos com IES do exterior (sobretudo bolsas-sanduíche); 4. A participação de docentes e doutorandos em eventos internacionais de alto nível; 5. A participação e financiamento internacional de projetos e outras atividades; 6. A participação de docentes em comitês, consultorias, editoria de periódicos e outras atividades no exterior (CAPES, 2016, p. 21). 
Nessa direção, serão apresentados alguns dados que indicam as principais tendências do processo de internacionalização na área da Educação, considerando os cinco programas que, no final de 2016, eram os programas de excelência, pela avaliação CAPES ${ }^{8}$. Um primeiro elemento a destacar é que um dos aspectos mais significativos para a internacionalização dos programas foi o intercâmbio de pessoas, principalmente pela viabilidade de mobilidade internacional de professores pesquisadores.

Por isso, o primeiro indicador a ser considerado é o crescimento do estágio pós-doutoral ocorrido por mobilidade internacional docente. Dos 320 docentes que compunham o quadro desses Programas em 2016, já 188 realizaram estágio pós-doutoral. Desse total, 131 (40,9\%) docentes participaram de estágio de pós-doutorado no exterior. Das 188 ocorrências, 72 $(38,3 \%)$ estiveram no período de 2010-2016, sendo que a grande maioria, totalizando 58 professores $(80,6 \%)$, contou com fomento, enquanto em 14 casos não houve apoio financeiro externo $(19,4 \%)$. Tal informação torna patente como o incentivo Capes, CNPq e, complementarmente, o apoio das Fundações de Apoio à Pesquisa Estadual (FAP), é imprescindível para sustentar a iniciativa de internacionalização dos programas.

Outro dado significativo indica o país para o qual se destinaram os professores em estágio pós-doutoral: Estados Unidos (23,1\%); Inglaterra (19,2\%); França (17,9\%); Portugal (15,4\%); Espanha (10,3\%); Alemanha, Argentina e México (2,6\% cada um) e Austrália, Canadá, Dinamarca, Grã-Bretanha (exceto Inglaterra) e Itália (1,3\% cada um) (PLATAFORMA LATTES, 2016).

Verifica-se, portanto, que a mobilidade docente tendeu a se efetivar na direção NorteSul, uma vez que só se justifica a solicitação de apoio financeiro para pesquisa internacional com mobilidade quando se trata de buscar conhecimento nos centros de excelência, tal como se coloca claramente no PNPG e a ENCTI. Esse fato, inclusive, reforçaria a indicação de outras áreas de conhecimento como prioritárias para investimento em pesquisa internacional ${ }^{9}$.

Dessa forma, não haveria como utilizar recurso público para pesquisar algum objeto que já estivesse sendo tratado pelos centros de excelência brasileiros, mesmo que esse intercâmbio,

\footnotetext{
${ }^{8}$ Foram coletadas informações dos Programas de Pós-graduação das seguintes instituições: PUC-Rio, UERJ, UFMG, UNISINOS e USP.

${ }^{9}$ Vale ressaltar que se justifica as priorizações indicadas pelo PNPG e ENCTI, deixa de considerar que o Brasil tem poucos centros de excelência em educação, principalmente se considerarmos que a pós-graduação é praticamente o único local de desenvolvimento de pesquisa em Ciências Humanas e, portanto, os centros de excelência existentes seriam atrelados à avaliação da pós-graduação, em outros termos, seriam os poucos programas 6 e 7 pela avaliação Capes.
} 
baseado em internacionalização passiva Norte-Sul ${ }^{10}$ (LIMA; MARANHÃO, 2009), fosse o primeiro passo para se construir a participação de brasileiros em redes de pesquisa ou grupos de pesquisas internacionais, que resultassem no intercâmbio de pesquisadores e formação de redes de pesquisa. Um elemento importante para se explicar o porquê da pouca participação da área educação, quando se trata de editais de pesquisa que envolviam mobilidade de pesquisadores para fora do país: dos 2205 editais localizados entre 2010-2016, envolvendo Capes e CNPq, 330 (15,0\%) contaram com participação de pesquisadores das áreas de Ciências Humanas, e em 68 (3,1\%) havia pesquisadores da área de educação, número bastante reduzido, mesmo quando considerado apenas as Ciências Humanas (20,6\% do total de participações das Ciências Humanas).

Um outro tópico evidenciado nos documentos foi a preocupação em definir a relação entre o processo de internacionalização e as exigências do mercado. Quanto à motivação pela internacionalização como necessidade de mercado ou fator de difusão do conhecimento e conhecimento compartilhado, a busca pela melhor nota de avaliação reflete uma competição que não pode ser ignorada. Afinal, traz incentivos econômicos que promovem a melhoria do programa. Tal problemática é tratada por França (2014), que lista alguns desses incentivos econômicos: recursos para despesas do programa, bolsas de estudo nacionais e internacionais para alunos, e editais específicos para atingir objetivos estratégicos, como a internacionalização da pesquisa, aqui estudada, e o equipamento de laboratórios. Nesse sentido, França (2014) enfatiza que os programas que investigava estavam cientes de que buscavam dar atenção à internacionalização, por ser uma exigência necessária para se chegar à excelência, mesmo com o entendimento de que uma internacionalização "ideal” seria a que assume o papel de interlocução com colegas e trabalhos diferentes, ancorados na realidade brasileira, não apenas valorizando a publicação, mas projetos conjuntos.

Uma das demandas tidas como mercadológicas, uma vez que possibilitaria a inserção competitiva do Brasil na disponibilização dos conhecimentos acumulado na área, é quanto à cooperação Sul-Sul. Essas parcerias, efetivadas pela formação de redes de pesquisadores, têm ocorrido, o que pode ser demonstrado pelas fichas de avaliação dos programas de excelência, existindo inclusive a proposição de que os centros brasileiros de excelência em educação têm o

\footnotetext{
${ }^{10}$ Por internacionalização passiva entende-se como a que está presente na maioria dos países semiperiféricos e periféricos da economia-mundo e seus resultados tendem a responder mais a interesses comerciais do que culturais, opondo-se à ativa, que está limitada a poucos países e se presta a criar condições que favorecem a emergência de uma espécie de internacionalização hegemônica e por isso mesmo capaz de exercer expressiva influência sobre a organização do sistema mundial de educação superior.
} 
compromisso de alavancar a área, sugerindo redes com a América Latina e a África ${ }^{11}$, por exemplo, mesmo sendo um trabalho mais difícil, até mesmo pela falta de investimento, tanto brasileiro, quanto dos outros países (CAPES, 2017).

Estas duas últimas iniciativas, por serem inovadoras na área de Educação, têm esbarrado em entraves burocráticos para o incentivo da permanência de discentes em solo brasileiro durante suas pesquisas de mestrado ou doutorado. Também há dificuldade de obtenção de linhas de financiamento de mobilidade de docentes e discentes para países da América Latina e da África, mesmo que já estejam com a cooperação regularizada, pois órgãos de fomento tendem a entender que a América Latina e África não se constituem como parceiros importantes em uma perspectiva de internacionalização. A título de exemplo, cite-se o edital n. 41/2017, especificamente voltado para projetos de internacionalização das IES no Brasil, quando apresenta, em seu anexo a "Relação dos países com os quais a cooperação científica e acadêmica com o Brasil tem se mostrado mais efetiva, [...] [nessa direção] ao menos 70\% dos recursos para parcerias devem ser alocados [para tais países]" (CAPES, 2018, p. 23). Na referida lista, do continente africano, consta apenas a África do Sul; da América Latina, Argentina e México. Todo o restante do grupo, 23 países, são europeus e/ou pertencem ao Bloco dos Países Emergentes (BRIC). Importa ressaltar que, dessa forma, cria-se um círculo vicioso: uma vez que os países em destaque seriam aqueles que menos contribuições demandariam, no campo educacional, do Brasil, isso com certeza colabora para um número pequeno de parcerias desenvolvidas, reforçando a impressão de que a área Educação não é demandante de projetos de internacionalização.

\section{Considerações finais}

Investigando, então, como a Capes avalia os programas de pós-graduação quanto à inserção internacional, é tratada neste artigo principalmente a mobilidade docente, seja de brasileiros para o exterior, seja de estrangeiros que procuram os Programas de Pós-Graduação existentes na área de Educação.

A questão fundamental era entender como a avaliação CAPES funcionou como elemento importante para se definirem as diretrizes de internacionalização dos programas de

11 Percebe-se, nos dados fornecidos pelos Programas, que todos participam do PEC-PG, recebendo discentes para mestrado e doutorado plenos no Brasil. No entanto, somente um programa tem uma linha de pesquisa direcionada a estudos com a América Latina, recebe alunos de países desse grupo e também estabeleceu um Dinter com uma instituição africana. 
excelência. Uma das respostas encontradas foi que historicamente o Estado no Brasil tem incentivado mais determinadas áreas, o que foi provado nos discursos das políticas do Plano Nacional de Pós-Graduação (2011-2020) e da Estratégia Nacional de Ciência, Tecnologia e Inovação (ENCTI 2016-2019). Foi mostrado ainda, por um lado, como essas diretrizes se materializaram via editais que promoveram mobilidade docente e apoio à publicação internacional, deixando patente a pequena participação das Ciências Humanas e, no seu interior, da Educação. Por outro, ao explicitar determinados parceiros internacionais como prioritários, a agência estatal reguladora da pós-graduação no país minimiza outros esforços de internacionalização, principalmente os sugeridos pela área de Educação na perspectiva Sul-Sul.

Já de posse dos resultados da avaliação do quadriênio 2013-2016, é possível perceberse elementos como as modificações internas aos programas, na direção de modificação estrutural de currículo, com a inclusão de linhas de pesquisa internacionalizáveis; a introdução de disciplinas com a possibilidade de serem ministradas por professores visitantes estrangeiros; e a preocupação com a inclusão de bibliografia em língua estrangeira nas ementas.

As estratégias desenvolvidas pelos programas revelam, portanto, que valorizam o que o SNPG tem direcionado, atendendo aos critérios para manter seus níveis de excelência e, consequentemente, obter financiamento da Capes e CNPq. Assim, tem direcionado a mobilidade docente e discente de forma a atender indicadores de inserção internacional, como a divulgação do conhecimento em periódicos internacionais ou internacionalizados.

Conclui-se o artigo reafirmando que a área de Educação faz ciência e precisa ter uma política de desenvolvimento científico que respeite as suas diferenças e necessidades, quando comparadas com outras áreas. Tornou-se um desafio fazer desta última a diretriz fundamental da política de avaliação da pós-graduação, que hoje estabelece, ao contrário, um mesmo padrão avaliativo para todas as ciências, apenas com possibilidade de uma pequena adequação em termos de pontuação ou prioridades. É crucial que cada área conte com incentivos públicos que propiciem o seu crescimento, não somente em relação aos programas da mesma área, mas também em termos de região geográfica.

Os desafios atuais já estão sendo defrontados pelos programas. O principal deles tem sido a crise econômica, com o consequente corte de verbas aprovadas, o atraso no pagamento de bolsas e de outros investimentos, a diminuição da mobilidade internacional docente e discente, e até mesmo a inviabilidade de tradução de artigos para publicação. Outros desafios devem ser enfrentados para que a Educação se fortifique e seja valorizada pelas políticas públicas como ferramenta de desenvolvimento econômico do país, com a criação de pesquisas que sejam não só úteis em nível regional, mas que tenham a visão de internacionalidade do 
conhecimento compartilhado. Especificamente para a docência, Morosini (2006, p. 43) ressalta o grande desafio de "[...] manter o protagonismo de decisões reflexivas em vez de se constituir em mero executor de políticas globalizantes". Estendendo a busca desse protagonismo a todas as etapas do fazer científico, acredita-se que a educação tenha um papel relevante a desempenhar nos processos econômicos, sociais e políticos que se desenrolam no presente, bem como no futuro próximo, nos quais a internacionalização da produção científica cada vez mais estará em destaque.

\section{Referências}

ANDRADE, Mariana Alves de. De Marx a Mészáros: a inseparável relação entre o estado e a reprodução do capital. In: PANIAGO, Maria Cristina Soares (org.). Marx, Mészáros e o Estado. São Paulo: Instituto Lukács, 2012. p. 11-27.

AZEVEDO, Mário Luiz Neves de; CATANI, Afrânio Mendes. Educação superior, internacionalização e circulação de ideias: ajustando os termos e desfazendo mitos. In: CATANI, A. M.; OLIVEIRA, J. F. de (org.). Educação superior e produçãa do conhecimento. Campinas: Mercado de Letras, 2015, p. 69-92.

BRASIL. Ministério da Educação. Coordenação de Aperfeiçoamento de Pessoal de Nível Superior. Plano Nacional de Pós-Graduação - VI PNPG. Brasília, 2010a. Disponível em: http://www.capes.gov.br/images/stories/download/Livros-PNPG-Volume-I- Mont.pdf. Acesso em: 30 mar. 2013.

BRASIL. Ministério da Educação. Coordenação de Aperfeiçoamento de Pessoal de Nível Superior. Plano Nacional de Pós-Graduação - VI PNPG. Brasília, 2010b. Disponível em: http://www.capes.gov.br/images/stories/download/Livros-PNPG-Volume-II- Mont.pdf. Acesso em: 30 mar. 2013.

BRASIL. Decreto no 7.642, de 13 de dezembro de 2011. Institui o Programa Ciência sem Fronteiras. Brasília, 2011. Disponível em: http://www.planalto.gov.br/CCIVIL_03/_Ato20112014/2011/Decreto/D7642.htm. Acesso em: 02 mar. 2014.

BRASIL. Ministério da Ciência, Tecnologia, Inovações e Comunicações. Estratégia Nacional de Ciência, Tecnologia e Inovação: 2016-2019. Brasília, 2016. 128 p.

CAPES. Documento de área 2016 - Educação. Brasília, 2016. Disponível em: http://www.capes.gov.br/images/documentos/Documentos_de_area_2017/Educação.pdf. Acesso em: 29 set. 2016.

CAPES. Documento de área 2017 - Educação. Brasília, 2017. Disponível em: http://avaliacaoquadrienal.capes.gov.br/. Acesso em: 29 set. 2017.

CAPES. Edital 41/2017 - Capes/PrInt - Relação dos países parceiros - Anexo 1. Brasília, 2018. Disponível em: http://www.capes.gov.br/images/stories/download/editais/02022018Edital-41-2017-Print-alteracao-anexo-1.pdf. Acesso em 15 mar. 2018.

DOURADO, Luiz Fernandes; OLIVEIRA, João Ferreira; CATANI, Afrânio Mendes. Políticas e gestão da Educação superior. São Paulo: Xamã, 2003. 
FRANÇA, Indira Alves. Avaliação da Capes e gestão de programas de excelência na área de educação. Rio de Janeiro, 2014. 249 p. Tese (Doutorado em Educação) - Departamento de Educação, Pontifícia Universidade Católica do Rio de Janeiro, Rio de Janeiro, 2014.

GOUVEIA, Flávia. Tecnologia nacional para extrair petróleo e gás do pré-sal. Conhecimento \& Inovação, Campinas, v. 6, n. 1, 2010. Disponível em: http://inovacao.scielo.br/scielo.php?script=sci_arttext\&pid=S198443952010000100010\&lng=es\&nrm=iso. Acesso em: 13 jun. 2018.

HARVEY, David. O novo Imperialismo. São Paulo: Loyola, 2004.

LIMA, Paulo César Ribeiro. Os desafios, os impactos e a gestão da exploração do pré-sal. Brasília: Biblioteca Digital da Câmara dos Deputados, 2008. Disponível em: http://www2.camara.leg.br/a-camara/documentos-e-pesquisa/estudos-e-notas-tecnicas/areasda-conle/tema16/2008-13035.pdf. Acesso em: 13 jun. 2018.

LIMA, Manolita Coreia; MARANHÃO, Carolina Machado Saraiva de Albuquerque. O sistema de Educação superior mundial: entre a internacionalização ativa e passiva. Avaliação, Campinas; Sorocaba, v. 14, n. 3, p. 583-610, 2009.

LEIS, Hector. O que significa um think tank no Brasil de hoje. Disponível em: http://www.institutomillenium.org.br/artigos/o-que-significa-um-think-tank-nobrasil-de-hoje/. Acesso em: 16 mar. 2017.

MOROSINI, Marília Costa. Estado do conhecimento sobre internacionalização. Educar, Curitiba, n. 28, p. 107-124, 2006.

NEVES, Lúcia Maria Wanderley; PRONKO, Marcela Alejandra. O mercado do conhecimento e o conhecimento para o mercado: da formação para o trabalho complexo no Brasil contemporâneo. Rio de Janeiro: EPSJV, 2008.

PAIVA, Flavia Melville. A Internacionalização da Pós-Graduação em Educação no Brasil: mobilidade e produtividade docente (2010-2016). 2017. Tese (Doutorado em Educação) - Universidade Federal de Mato Grosso do Sul, Faculdade de Educação, Campo Grande, 2017.

PEIXOTO, Maria do Carmo. Educação como bem público, internacionalização e as perspectivas para a Educação superior brasileira. In: OLIVEIRA, J. F.; CATANI, A.; SILVA JUNIOR, J. dos R. (orgs.). Educação superior no Brasil: tempos de internacionalização. São Paulo: Xamã, 2010. p. 29-36.

PLATAFORMA LATTES. Brasil, 2016. Disponível em: http://lattes.cnpq.br/. Acesso em: 16 mar. 2017.

SILVA JUNIOR, João dos Reis; KATO, Fabíola Grello. PNPG (2011-2020): certificação em massa, internacionalização e mercantilização do conhecimento. In: SILVA JUNIOR, João dos Reis; CATANI, Afrânio Mendes; CHAVES, Vera Jacob. Consequências da mundialização da universidade pública brasileira Pós-graduação, trabalho docente, profissionalização e avaliação. São Paulo: Xamã, 2012. p. 11-28.

VISENTINI, Paulo Fagundes. A projeção internacional do Brasil 1930-2012. Rio de Janeiro: Elsevier, 2013. 